\title{
The influence of training in buying behaviour and willingness to pay for wines. The case of the fortified wines of the Montilla-Moriles PDO
}

\author{
Luis Navarro García ${ }^{1}$, Carmen Egea Bartual², and Pilar Ramírez Pérez ${ }^{2}$ \\ ${ }^{1}$ Consejo Regulador de la DOP Montilla Moriles, 14550 Avda. José Padillo Delgado, s/n, Spain \\ 2 IFAPA Centro de Cabra, 14940 Antigua Ctra. Cabra-Doña Mencía, Km. 2.5, Spain
}

\begin{abstract}
The Spanish fortified wines (with alcohol content exceeding 15\% by volume) are produced only in Western Andalusia (Spain), being awarded with a Denomination of Origin (PDO). They are products where quality is associated with complex changes during the aging under "velo de flor" (film of yeast) and/or for a long time. The consumption of these kind of wines has decreased as a result of the changes in the recent drinking consumption habits, and because of the rise of other more popular alcoholic drinks. This study is based on a survey made to 1990 Andalusian consumers, according to a stratified quota sampling method, based on the sociodemographic characteristics of the consumers target population. Methodology used questionnaires (frequencies, percentages, means and measures of variability, depending on the type of variables) and experiments that explain the variability of the criterion variables taken into account (in our case buying behaviour and willingness to pay - WTP). Contingency Tables, Analysis of Variance, CHAI Analysis, and Cluster Analysis were the statistical methods used here. The results of this work show some threats over fortified wines, due to the old population consuming these types of wine, and the narrow area where these wines are frequently consumed. It has also to be noted that preferences of younger people aim to other competing alcoholic drinks (white young and red wines). The information and training courses consumers have on fortified wines affects positively on WTP, therefore, training strategies are suggested to get this objective.
\end{abstract}

\section{Background}

The interest of consumers for local quality products is increasing nowadays, and therefore, there is growing interest in understanding the causes of the demand for these products, and consumer willingness to pay (WTP) for them. The frequent small size of these firms bounds the existence of economies of size, so they have to take into account other strategies to value their singularities. Some of these firms use intuitive pricing policies without studying the WTP for their productions [1], although there is a profuse literature on this subject [2]. Most of the WTP studies regarding foodstuffs deal with their environmental attributes, such as landscape [3], or with organic productions $[4,5]$. There are also many references concerning wine, for instance, organic wines [6,7], those with PDO [8], both ones [9], or functional wines with special characteristics $[10,11]$. It has been found that WTP is associated positively with the quality of the product itself, and with the information consumers have on its characteristics [12-14].

The most common methodology used to study WTP ranges from descriptive surveys and the multivariate analysis of the results gotten from them, to experiments designed to study the cause-effect relationships between variables. Conjoint Analysis, Dichotomous Choice Models, or Contingent Analysis are the most analytical tools used $[3,8,11]$.

This paper deals with consumer's WTP for the most significant types of wines from Montilla-Moriles DOP (MM), including Fino, Oloroso, Amontillado, and Pedro
Ximénez. ${ }^{1}$ Special attention was paid to the Fino wine, the most genuine wine produced in MM. This wine comes from Pedro Ximénez grapes that are lightly crushed to get "mosto yema" (free running grape juice), which, after fermentation, is aged in American oak barrels. This aging occurs under a layer of yeast, spontaneously developed, that protects these wines from oxidation, being the responsible agent of the biochemical and organoleptic changes developed during this time (biological aging). The explanation of the singularities of fortified wines overtake the purpose of this study, so it is suggested to read [15].

The consumption of MM wines has been declining in recent years, despite their quality has improved at the same time (controlled fermentation systems, stabilization by cooling...), for many reasons, such as the appearance of other alcoholic beverages to the liking of today's consumers, for example, beer, and young white or red wines.

\section{Material and methods}

A 1990 consumer survey was made, 645 to consumers from the MM production area, 689 to the ones living in rest of the province of Córdoba, and 161 to consumers from other

\footnotetext{
${ }^{1}$ Montilla-Moriles PDO is located in the southern part of Córdoba province, in Andalusia, Spain. Pedro Ximénez is not a fortified wine properly, but it is a sweet liqueur wine. Nevertheless it is included in this study because of its economic importance and uniqueness.
} 
Andalusian places. A structured self-administered questionnaire was developed, using mainly closed questions. Sampling was carried out using quotas according to the study target population consumer sociodemographic characteristics (sex, age, and educational level). Questionnaire content includes wine consuming and buying behaviour (in general and regarding MM wines), information on the characteristics of MM wines, and willingness to pay for each of their types.

Descriptive analysis, frequencies and percentages, have been made for nominal variables; measures of central tendency and dispersion, for numeric/scale variables. To end with, statistical analysis for testing hypothesis (Contingency Tables, CHAID analysis, and ANOVA) were performed.

\section{Results and discussions}

\subsection{Consumer behaviour}

MM wine consumption frequency for the overall consumers in the sample $(40.4 \%)$ is sporadic, being more heavy consumers those living closer to the production area MM $(44.8 \%$, and $28 \%$ of the residents in the MM production area and the rest of the province of Córdoba, respectively, drink these wines several times a week; the rest of the sample components take MM wine sporadically or never). This frequency of consumption is explained by the consumer's sociodemographic variables. Men over 50 years old, and living in MM area are the most heavy consumers (81.5\% of them consume MM wine daily or several times a week). On the other hand, the segment of women under 30 consume these wines rarely or never $(80.5 \%)$. These results show the loyalty the oldest population residing in the MM area have to these wines. Fino, the most popular of the MM wines, is the most preferred in that area of production, declining in popularity as we move away from it (residents of other Andalusian provinces prefer in the first place to consume red wines or the fruity young white ones).

\subsection{Buying behaviour}

The consumers in the sample have not sophisticated buying behaviour. Wines are for them an ingredient that go together with other foodstuffs in their social celebrations, delegating into retailers the selection of wines, whose policies are regularly focused on profitability rather than on quality. Buying MM wines, especially in the area of production, is usually done in bulk; consumption is used to be doing "en rama" (without filtering or conditioning for preservation). Both habits, due to local preferences, give a lower commercial value to these wines, besides could sometimes present problems regarding traceability, an essential PDO condition.

\subsection{Information and training}

The consumers in the sample do not appear to be informed about the characteristics of the MM wines (only 19.8\% said they know them), being the older than 50 years and residing in MM those who say to have an adequate information of them $(66.3 \%)$. Conversely, the youngest components of the sample, residing outside MM area, barely know the characteristics of these wines $(0.8 \%)$. Fino and Pedro Ximenez are the best known and consumed MM wines. Oloroso, and Amontillado, with a marginal volume of production in MM, are, on the other hand, less known.

The information consumers have on the characteristics of MM wines influences their consumption frequency: $49 \%$ of those who state to know their characteristics consume them daily or several times a week (compared to $28 \%$ of the components of the overall sample). This variable also explains positively the habits of buying wines. Performed a Cluster Analysis including the buying behaviour variables, two clusters were found, the first one including consumers more sophisticated in buying wines, and the second one representing consumers who just buy cheap wines. Those people with more information on the characteristics of MM wines are significantly better represented in the first group of wine sophisticated buyers. There is a significant higher percentage of the best informed consumers in the first segment $(55.6 \%)$ than in the cheap wines one $(44.4 \%)$.

Consumers have a scarce level of training about MM wines: There are a very few consumers in the overall sample who have received a training course (13.9\%) and a slightly higher percentage of those who have attended to a guided tasting seminar $(21,5 \%)$, being women, and persons under 30 years, on the other hand, who are more interested in training courses.

\subsection{Willingness to pay}

WTP for MM wines varies widely. The WTP distribution is shown in Table 1. If the statistical mode were used to compare the WTP for the different wines, it can be seen that Pedro Ximénez is the wine with the highest WTP $(41.9 \%$ of the sample would pay over $7 € /$ bottle $3 / 4 \mathrm{~L}$ ), followed by Oloroso and amontillado, and, to end with, Fino.

If prices class mark intervals were used to analyse WTP (0 price units for those who would pay anything for a wine; 1 price unit for those who would pay less than $4 € /$ bottle, 2 price units for the ones paying $4-7 € /$ bottle; and 3 price units regarding people paying more than $7 € /$ bottle) the WTP distribution is shown in Table 2. WTP for Pedro Ximénez wine is higher than for Oloroso/amontillado, and Fino wines. These means are significantly different to each other (ANOVA).

Table 1. WTP for fortified wines (\%; €/bottle $3 / 4 \mathrm{~L})$.

\begin{tabular}{|l|c|c|c|c|}
\cline { 2 - 5 } \multicolumn{1}{c|}{} & $\mathbf{0 €}$ & $<\mathbf{4 €}$ & $\mathbf{4 - 7} €$ & $>\mathbf{7 €}$ \\
\hline Fino & 5.4 & 37.7 & 51.0 & 5.8 \\
\hline Oloroso/Amontillado & 8.7 & 20.7 & 51.0 & 19.5 \\
\hline Pedro Ximénez & 5.9 & 8.7 & 43.4 & 41.9 \\
\hline
\end{tabular}

Table 2. WTP (class marks - price units).

\begin{tabular}{|l|c|c|c|c|}
\cline { 2 - 5 } \multicolumn{1}{c|}{} & Min & Max & Mean & St. error \\
\hline Fino & 0 & 3 & 1.5 & 0.01 \\
\hline Oloroso/Amontillado & 0 & 3 & 1.8 & 0.02 \\
\hline Pedro Ximénez & 0 & 3 & 2.2 & 0.01 \\
\hline
\end{tabular}


Table 3. Knowledge of the characteristics of wines and WTP (units).

\begin{tabular}{|l|c|c|c|c|}
\cline { 2 - 5 } \multicolumn{1}{c|}{} & \multirow{2}{*}{ Mean } & \multicolumn{3}{c|}{ Knowledge } \\
\cline { 2 - 5 } \multicolumn{1}{c|}{} & & Yes & No & Sig. $^{\mathrm{c}}$ \\
\hline Fino & 1.57 & 1.65 & 1.42 & $* * *$ \\
\hline Oloroso/Amontillado & 1.81 & 2.13 & 1.58 & $* * *$ \\
\hline Pedro Ximénez & 2.21 & 2.44 & 1.79 & $* * *$ \\
\hline
\end{tabular}

a $* p \leq 0.05 ; * * \leq \leq 0.01 ; * * * p \leq 0.001$.

There is a high variability on WTP distribution according to the range values (difference between minimum and maximum). This variability is explained by sociodemographic characteristics of consumers (CHAID Analysis), resulting that the consumer segment living in the area $\mathrm{MM}$ are willing to pay higher prices for Fino wine (1.71 pcs.), and more than that those with university degree (1.89 pcs.) belonging to the last group. Within those residing outside this area, women appreciates more Fino wine (1.61 pcs.). Amontillado and Oloroso are also appreciated more in the MM area regardless of sex, age or educational level (1.91 pcs.); in the rest of the areas are women who has the highest WTP (1.87 pcs.). In the case of Pedro Ximénez wine, the first variable discriminating is sex, being women who would pay more for these wines ( 2.37 pcs.), and much more women living in MM (2.57 pcs.). The niche with the lower WTP for Pedro Ximénez includes the youngest men living outside of the province of Cordoba (in the rest of Andalusia).

Another important source of variability of the WTP is the information consumers have about the MM wines features. Table 3 shows, unquestionably, that consumers with information would pay significantly more for these wines (t-Student, independent samples).

\section{Conclusions and recommendations}

MM wines, while unique because of their making and organoleptic attributes, are complexes wines that claim for culture to be appreciated properly. They are competing nowadays with other wines easier to like, and with a better marketing (included in wine lists, presented in wine basked, served in luxury cups...) being attractive for younger people and women. On the other hand, MM wines, as this study shows, are considered old fashioned wines consumed by older people. Studies pointing out wine consumer preferences may help to understand the wine features young consumers like most (least alcohol content, more aromatic, ...). Since information on the MM wine culture encourage people to pay a premium for them, training programs are suggested directed to the youngest people, and women.

\section{References}

[1] C. Grebitus, L. Lusk, R. Naiga. Ecological Economics. 88. pp. 67-75 (2013)

[2] K.B. Monroe, J.L. Cox. Marketing Management, 10 (3), pp. 42-46 (2001)

[3] C. Breidert, M. Hahsler, T. Reutterer. Innovative Marketing (2006)

[4] T. Tempesta, R. Giancristofaro, L. Corain. Food quality and preference. 21, Num. 7, pp. 827-836

[5] A. Krystallis, G. Chryssohoidis. British Food Journal, 107, Iss. 5, pp. 320-343 (2005)

[6] F. Ureña, R. Bernabeu, M. Olmeda. International Journal of Consumer Studies, 32, Iss. 1, pp. 18-26 (2008)

[7] R. Bernabeu, M. Brugarolas, L. Martínez Carrasco, M. Díaz. British Food Journal, 110, Iss. 2, pp. 174-188 (2008)

[8] D. Skuras, A. Vakrou. British Food Journal, 104, Iss. 11, pp. 898-912 (2002)

[9] R. Bernabeu, L. Carrasco. British Food Journal 110, Num. 2, pp. 174-186 (2008)

[10] M. Uros, V. Puskas, V. Vesna et al. Journal of the Institute of Brewing. 120, Num. 2, pp. 149-154 (2014)

[11] C. Holmquist, J. McCluskey, C. Ross. American Journal of Agricultural Economics, 94 (2), pp. 556-561 (2011)

[12] L.M. Albisu, J.A. Domínguez, J.L. Alejandre. Comunicaciones INIA, Serie Economía, Num. 21 (1989)

[13] S. Lecocq, T. Magnac, M. Pichery, M. Visser. Annales d'Economie et de Statistique, Num. 77, pp. 38-57 (2005)

[14] C. Laporte. XXVII World Congress of wine and vine. Bratislava (2002)

[15] M. López-Alejandre. Los vinos de Montilla-Moriles. Consejería de Agricultura $y$ Pesca, JUNTA DE ANDALUCÍA (2000) 